\title{
Effect of high intensity light irradiance on CuInSe2 thin films
}

\begin{abstract}
CuInSe2 has been a good candidate for photovoltaic material due to its direct band gap and high absorption coefficient. As the stability of photovoltaic are generally dependent on the aggressive environment, i.e. sun light, the CuInSe 2 thin film can degrade after long exposure of high intensity light irradiance. The present study reports on the effect of high intensity light irradiance to the electrical and optical properties of thermal evaporated CuInSe 2 thin films. The thin films were exposed to light intensity of $250 \mathrm{~W} / \mathrm{m} 2,500 \mathrm{~W} / \mathrm{m} 2,750 \mathrm{~W} / \mathrm{m} 2$, $1000 \mathrm{~W} / \mathrm{m} 2$ and $1500 \mathrm{~W} / \mathrm{m} 2$ using halogen lamp. We noticed an increasing trend in resistivity after light exposure at all intensities due to the increase of light-induced defects in the films which act as recombination centre for electron-hole pair. Crystallinity of CuInSe2 thin films decreases with increasing intensity of light exposure as a result of light-induce defect. CuInSe2 thin films are found to have higher optical band gap compared to reported $1.01 \mathrm{eV}$ due to the amorphous structure of the film and relatively higher surface roughness.
\end{abstract}

Keyword: CuInSe2; Electrical; Light degradation; Optical; Vacuum evaporation 